\title{
THE HBIM ANALYSIS OF THE GEOMETRY TO UNDERSTAND THE CONSTRUCTIVE TECHNIQUE: THE USE OF THE TROMPE VOLUME IN A BRICK VAULT
}

\author{
D. Attico ${ }^{1}$, A. Turrina ${ }^{1}$, F. Banfi ${ }^{1 *}$, A. Grimoldi ${ }^{2}$, A. Landi $^{2}$, P. Condoleo ${ }^{3}$, R. Brumana $^{1}$ \\ ${ }^{1}$ Department of Architecture, Built Environment and Construction Engineering, Politecnico di Milano, Milan, Italy \\ (fabrizio.banfi, raffaella.brumana)@ polimi.it \\ ${ }^{2}$ Department of Architecture and Urban Studies, Politecnico di Milano, Milan, Italy \\ (alberto.grimoldi, angelogiuseppe.landi)@polimi.it \\ ${ }^{3}$ Department of Civil and Environmental Engineering, Politecnico di Milano, Milan, Italy \\ paola.condoleo@polimi.it;
}

KEY WORDS: Geometry, brick vault, trompe, constructive technology, 3d model, HBIM, NURBS, generatives, cloister vault, dome

\begin{abstract}
:
The construction of brick-vaulted systems between the $16^{\text {th }}$ and $18^{\text {th }}$ centuries is a typical mark among the noble buildings in large part of Northern Italy. Nowadays they are still a witness of a high level of constructive knowledge by workers, formalized in historical treatises and manuals supporting a literature of theories and practices known since ancient times. The way a vault is geometrically built, regardless of its typology, is not unique and it differs in treatises, according to its location in time and space. The consequence is the generation of "mixed" solutions, where the result of the final volume is achieved by the integration of different generative models and spatial solutions. The observation of cloister vaults, apparently similar to each other but built adopting different constructive techniques within a single building, Magio Grasselli Palace in Cremona, helped to understand this topic.
\end{abstract}

\section{INTRODUCTION}

\subsection{A short overview of brick vaults dissemination}

Brick vaults in Northern Italy, built between the $16^{\text {th }}$ and $18^{\text {th }}$ centuries, are characterised by a wide variety of types and constructive solutions: many different arrangements (apparecchiatura in Italian), such as in stereotomy, may correspond to the same shape, though elementary - a cloister vault, a groined vault, a pendentive dome. The use of bricks, however, also changes the geometry: the difference is not immediately visible, but digital survey techniques quickly highlight it.

In the particular case of cloister vaults, although this typology has been codified in many treatises, actually built structures differ from the ideal model as a result of skills declined differently, following local constructive methods and connotations (Brumana et al. 2017). The richness of types and the variety of solutions suggest a parallel with the contemporary French stereotomy. Like stereotomy, the construction of complex brick vaults requires not only expert bricklayers and master masons but also technicians and intellectuals who possess extensive knowledge of geometry and, in general, of architecture. In the $18^{\text {th }}$ century, the flat Catalan vaults appeared in the treatises, but they coexist with one-layer brick vaults, an already well-known technique (Grimoldi and Landi, 2012). Certain figures - especially the intersections (pénétrations) of solids of revolution - emphasize the links between the stereotomic construction and brick vaults. Guarino Guarini's works, first in Latin (Euclides adauctus, Guarini, 1673) and then in Italian (the chapter dedicated to the "Iconografia gittata" of the Architettura Civile, entirely published only in 1737), show how the knowledge on the stereotomy concepts - directly known by the French literature was considered in the Italian qualified practices. With conscious pride, Guarini gives an unusual space in the treatise of architecture to vaults, codifying architectural types and figures already known. Recent research on these themes coincides with the studies on Guarini himself and, more generally, on the Piedmont Baroque. The rest of the contemporary bibliography is more limited, also when focused on the northern regions of Italy, although those regions boast earliest examples and variations on these themes often more complex. The constant search to make the construction of the vaults faster and cheaper corresponded with the need to replace the wooden structures, because wood became increasingly rare and expensive (Wendland, 2008). This aim, therefore, required less weight and more limitations on the quantity of wood needed for complex and continuous centering. This building economy also involved increased popularity of the vaults. In this paper, a particular example of cloister vault from a well-documented case, the Magio Grasselli Palace in Cremona (Figures 1-2), is presented.

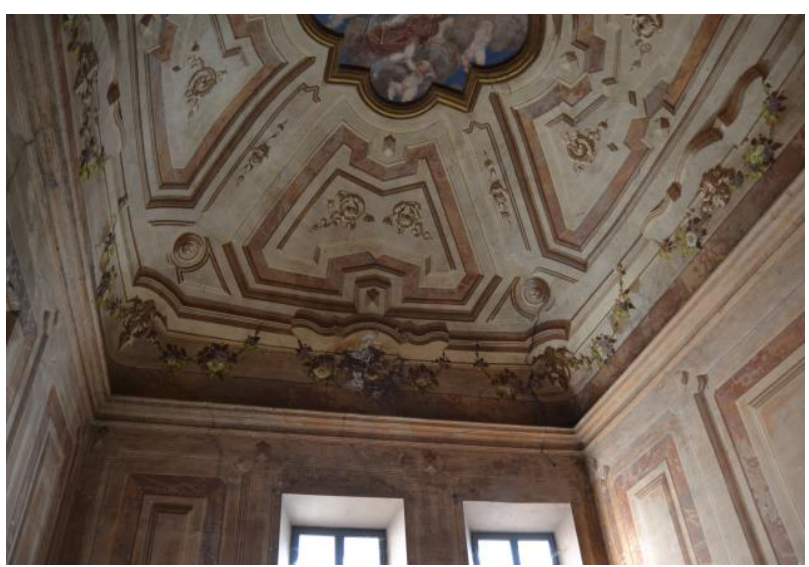

Figure 1. Magio Grasselli Palace: intrados of the staircase vault (Room 1.26).

\footnotetext{
* Corresponding author
} 


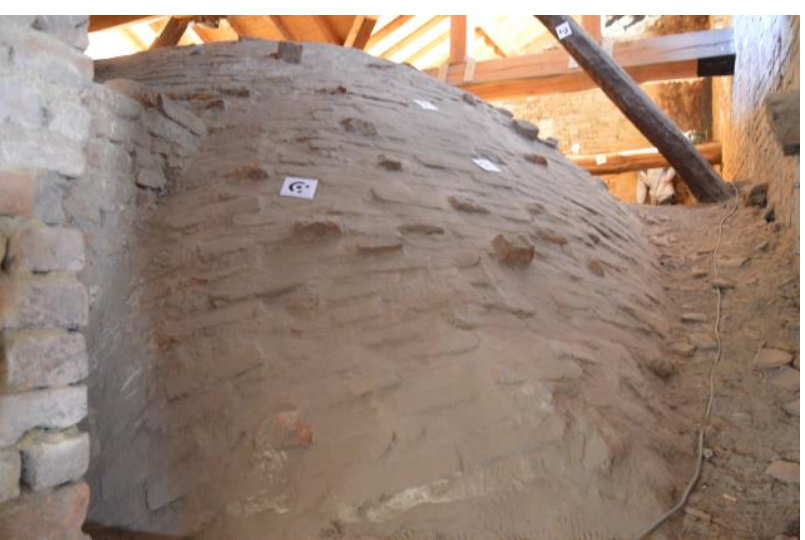

Figure 2. Magio Grasselli Palace: extrados of the staircase vault (Room 1.26).

\section{THE TROMPE IN HISTORICAL TREATISES}

Starting from this premise, the classification of vaults turns out to be a system with infinite variables, which would bring difficulties even in the choice of the most basic parameters to be considered.

The term trompe in the stereotomy treatises defines a small vaulted system normally built out of stone blocks, whose role is to support an overhanging element in order to spread the weight out to the walls, a sort of a fillet complex shape. This vault, voûte suspendue en l'air, as Delorme (1561) says, was used to support small hanging elements without ground support by integrating geometric methods into the principles of statics. There are many examples of trompe applied as connections to set up vaults and domes. Indeed, these structures can transform geometries by knowing their start and ending profiles. Sometimes, however, the individual parts are connected in such a way as to create an uniform continuous structure no longer recognizable at first glance. Unfortunately, the literature about this vault typology is not very rich. Guarini provides a first indirect reference, which is a cloister vault seen as penetration of four semi-cones, whose vertices correspond to the corners of a square room, cut by two planes perpendicular to each other and perpendicular to the generatrix (Guarini, 1737; Figure 3).

Another indirect reference could be found in Guarini's treatise (1737) where the author describes a structure consisting of the interpenetration of solids: on the rectangular plan of the room, a vault is constructed as the interpenetration of four cones in a rotation half-ellipsoid. Considering the construction of domes, the pillars very often support the arches, amongst which pendentives are built and cut diagonally. In order to keep the spherical pendentive that way, it must originate from just one point, where the two arches that define it get connected. Ending in a segment of a straight line, although very short, the curved surface must be adapted. According to stereotomy, the process is called gauchissiment. As an alternative, it is possible to build barrel vault wedges that are penetrated by a cylinder (or by a right ellipsoid) of the dome drum. In this case, the penetration of the drum line in the pendentive is an arch of the inclined circle, and the skill lies in hiding the inclination in the thickness of the springer, that juts out from the plan of the pendentive.

Guarini, therefore, proposes to build an ellipsoidal shell, planned on four arches rotated by $45^{\circ}$ about the major axis of the room, with the pendentives' plan lying on the middle of the sides and can present variable widths. The easiest way to gauchir is to gradually pass from a springer line to an inflected surface of the pendentive. There are, however, other alternatives to resolve the ellipsoid penetration into cylindrical segments of pendentives (Frezier, 1737-1739; Figure 4). Guarini does not explore such considerations, because, in practice, the bricks construction and the overlying plaster provide a vast space to connect the surfaces, if desired. Within this framework, it is possible to measure the boundaries of stereotomy influence over Guarini and more generally over the construction of vaults in Italy during the second half of the $17^{\text {th }}$ century.
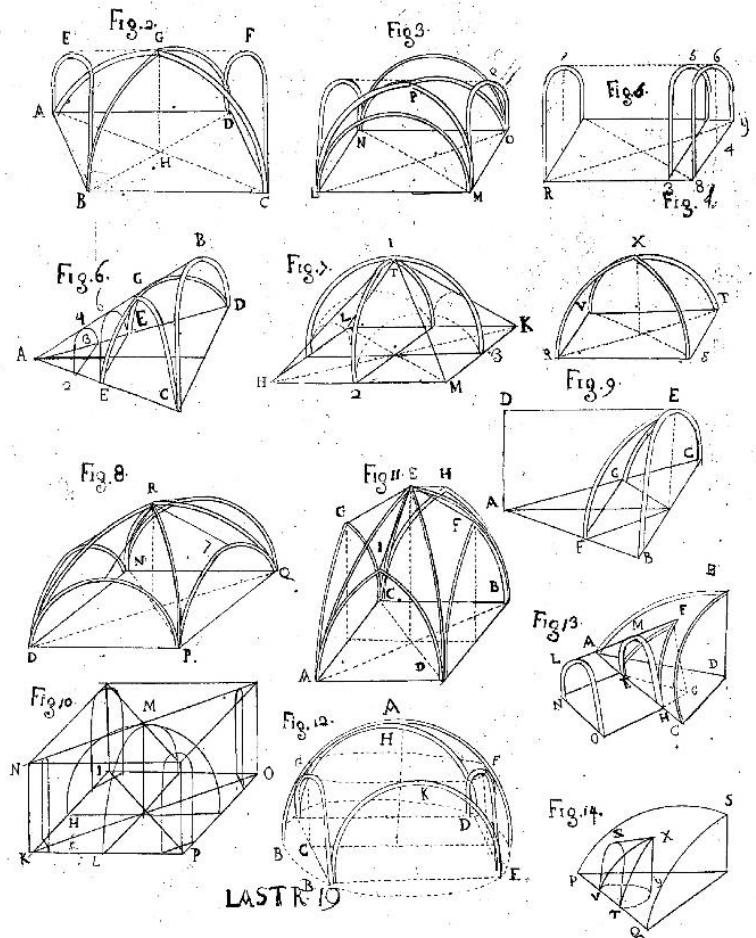

Figure 3. G. Guarini, Architettura Civile, Torino 1737, lastra XIX, trat. II.

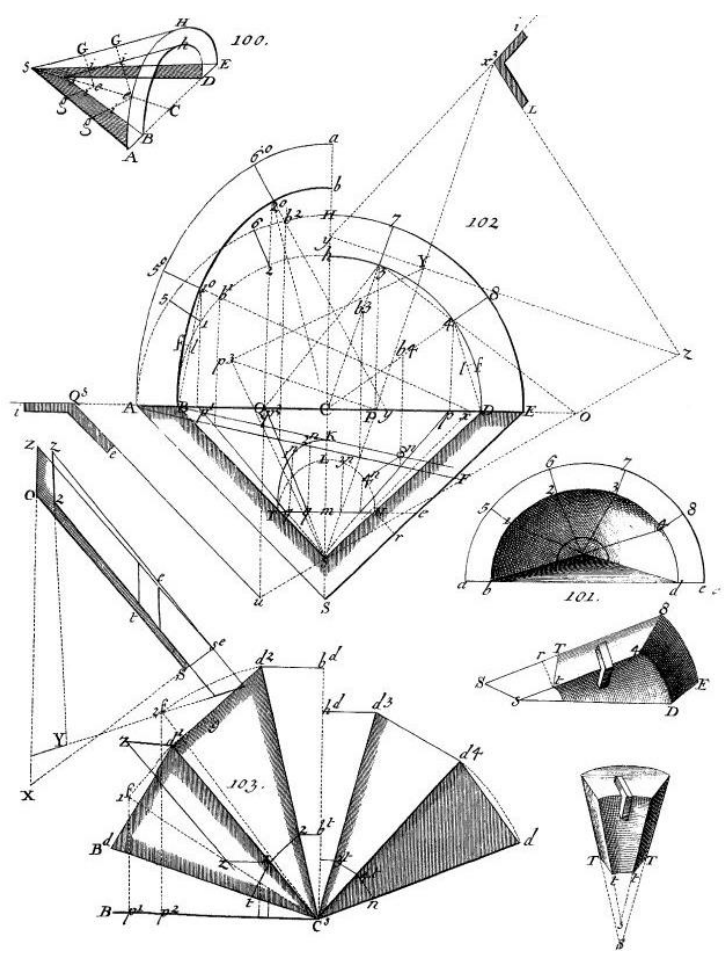

Figure 4. M. Frezier, Conical trompe, tav. 62, Volume IV.

\section{THE VAULTED STAIRS HALL OF MAGIO PALACE}




\section{AND ITS CONTEXT}

The staircase vault of Magio Grasselli Palace offers a peculiar evolution of the masonry pattern, and differs due to a geometric shape which falls, only partially, into the typology of a cloister vault. This structure dates back to the second half of the $16^{\text {th }}$ century, and is one of the restoration works of a great riforma of the palace carried out by the architect Pescaroli (Landi, 2011). The element of the stair became crucial to align the rooms, not only in Magio Palace but also in many noble buildings renovated in the same century, and all of this had led to the introduction of a big vault to cover the room. Looking at the intrados, the shape of the vault is quite similar to a cloister vault, but with a clear strange curved shape that does not fit with the "cloister" definition and classification. The connection joints of the four corners disappear as they get closer to the top. Furthermore, there is a sunken medallion in the middle at a level lower than the intrados profile.

This example also provides an important confirmation from the static point of view, since the relatively thin thickness may raise doubts about the vulnerability of the vault. As regards the monumental staircase, the vault is probably the most successful example both in terms of size (dimensions in braccia cremonesi) and design complexity: in fact, it was built at the meeting point of the ancient walls of the Magio magna Domus and an adjoining house, in an irregular shaped room lacking a perimeter wall. It is a cloister vault with a polycentric curvilinear profile (a basket handle arch) on its lower surface: the profile, unusual even if compared to other vaults in the palace, is characterised by the distinctly vertical slope of the four coves and a summit (corresponding with the central medallion) which is substantially flat. Bricks are laid edgewise, diagonal to the plane of the imposts which in this case form a series of pointed arches of different radius at each corner, adapted to the irregularity of the room. The corners are not visible, and the surface, being continuous, would allow the decoration to be independent of the articulation of the vault (Figure5).

The peculiar geometric profiles suggest that the skilled timber labour, needed to build a complete centering, had become a too significant expense in the construction process also in Cremona: the scarcity of timber, high cost and complexity of the realization of provisional works led to the necessity of introducing different types of vaults, in which the bricks curving made the use of the complete centering superfluous. The laying of the bricks reduces the use of timber, creating a vaulted system that was selfsupporting also during construction. The bricks of the four coves and those employed to build the central medallion are the same size $\left(30 \times 13.5 \times 9.5 \mathrm{~cm}^{3}\right)$ and were sufficiently sturdy to effectively withstand shear stresses.

In the wing of Raimondi Palace (also in Cremona) overlooking the street, behind the famous Botticino façade (Landi, 2019), there are five large rooms on the ground floor, covered by cloister vaults, similar in size, perhaps built by the mid- $17^{\text {th }}$ century. More in detail, three of them are nearly square. In the corners, bricks on soldier are arranged in arches inclined by $45^{\circ}$ to the walls and to the horizontal plan of the springer. Raising gradually until a perfectly vertical arrangement - a masterful example of gauchissement - they delimited a sort of sail vault, namely progressing from four irregular cones in the corners to a sphere cut in the middle. On this basis, another typology of vaults with similar arrangement can be found in Palazzo Roncadelli Pallavicino Ariguzzi (Cremona).
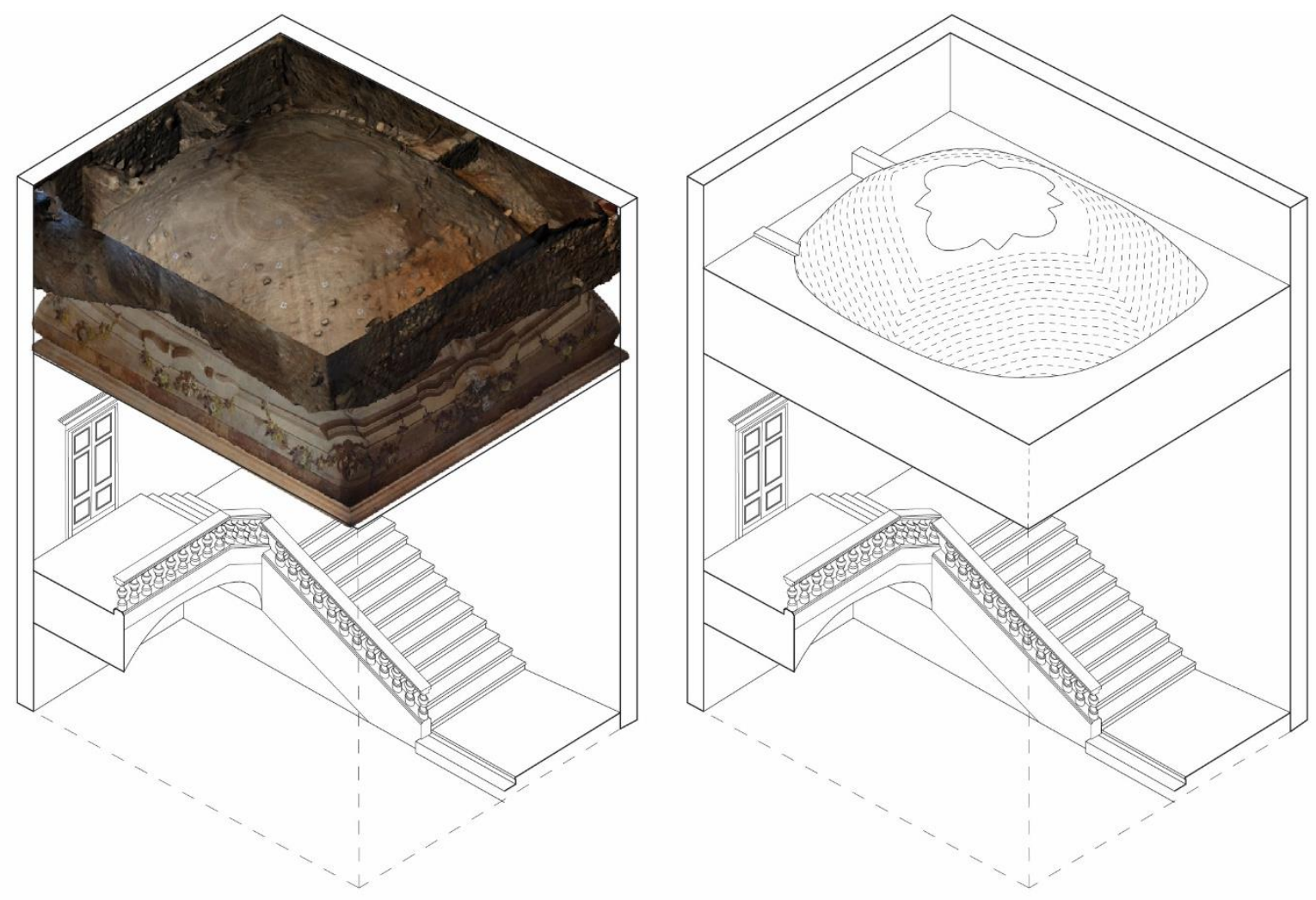

Figure 5. Axonometric view of the staircase room showing the overlapping of two 3D georeferenced orthoimages of the vault intrados and extrados - that allows to better understand the arrangement of the bricks. 


\subsection{Survey and geometric analysis}

The in-depth observation of cloister vaults, apparently similar to each other, reveals that they are often built adopting different constructive techniques, even within a single building: Magio Grasselli represents an example of this fact. The differences between vaults are not always clear from preliminary analyses, but they become more evident after a more accurate investigation based on the comparison between the reading of the traces through accurate digital (TLS, photogrammetry) and thermographic surveys with archive sources and the study of treatises.

Nowadays, the availability of several procedures, phases and tools for carrying out a survey allows to draw reliable assumptions about the construction methods and the execution time (Oreni et al., 2013).

The first tool is certainly the point cloud obtained from laser scanner techniques that allows to accurately identify the twodimensional profiles by cutting the surface at various points. Such a survey firstly aims to extract the main profiles that, through the movement of rotation and translation in space, ideally generated the final 3D geometry. Certainly, cutting the structure by different planes is useful to detect shape discontinuities of the different surfaces. However, this is not the case in Magio Palace. Moreover, the choice of section planes shall be supported by the observation of the vault arrangement, readable from the extrados. The photogrammetric reconstruction of the extrados allows the construction of a 3D model whose bricks have been identified and traced using the 3D orthophoto (Figure 6). An accurate dimensioning and a correct overlap of the photogrammetric model of the extrados, related to the intrados survey represented by the point cloud, make it possible to obtain a complete $3 \mathrm{D}$ result, where two different surveying techniques can interact with each other and models can be analysed together (Brumana et al. 2018). The availability of combined techniques, however, does not cover the lack of information related to specific points of the vault: it is not possible, for example, to identify the masonry

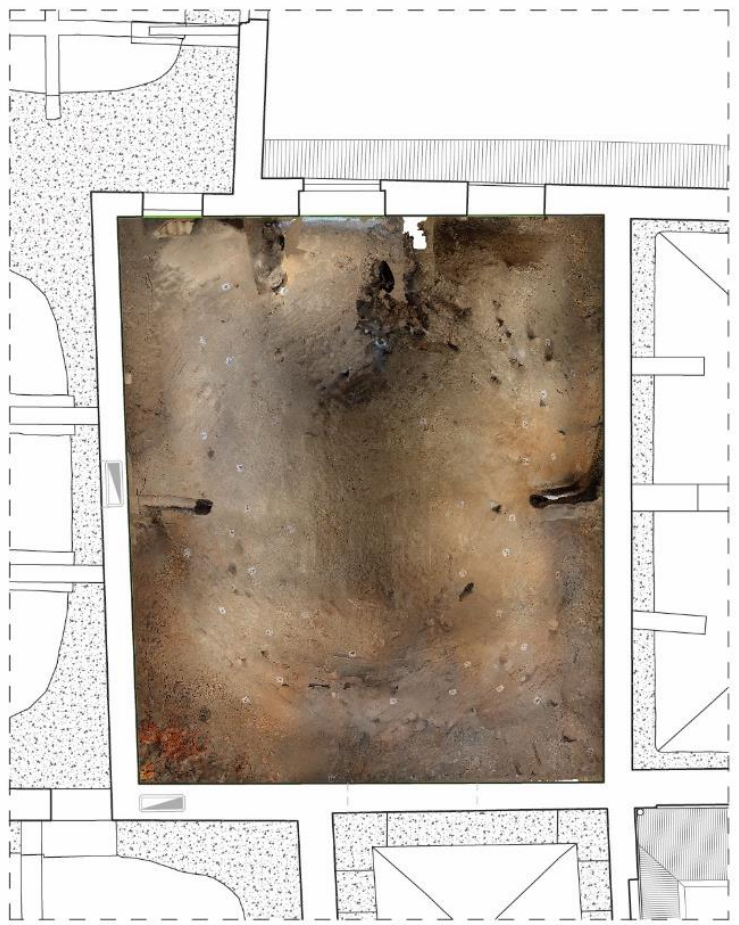

pattern of those parts hidden by mortar plaster or spandrels at the extrados; therefore, the use of thermal imaging is necessary to integrate missing information. Consequently, combining different surveying techniques turns out to be a correct approach The analyses carried out are based on a unitary model where all information about geometry and constructive technology are contained.

The first necessary investigation for this purpose consists of observing the profiles obtained by vertical sections of the point cloud following the section planes defined by vanishing point lines at the extrados. After looking at discontinuities, the next step aims to verify the geometry of these profiles. Despite approximations necessarily emerging from the presence of a plaster layer, the section at the intrados of the element is generally preferred for the vault reconstruction thanks to its smoothness, unlike the extrados. Despite the presence of a minimum visible deviation, profiles similar to semi-circular shapes are extracted in both transverse and longitudinal sections. In addition, however, a central almost straight segment related to the length of the medallion is introduced. The result is a profile repeated in all the axial sections of the vault, similar in size and curvature, which describes a hemispherical geometry or, more accurately, twoquarters of a sphere connected by a portion of a cylinder, to fit the vault to a rectangular plan (Figure 7).

This simple checking leads to identify the shape of a sphere as a central generative element of the vault in question; this sphere is extended by the introduction of a portion of the cylinder to deal with the rectangular plan of the room (Figure 8). In this way, the first solid is obtained - in this case, the sphere - represented by Guarini and confirmed by the geometry of the vault under investigation.

As with all the groin vaults, the spherical surface is cut across the four cardinal directions, that in this case are inclined differently to the plan in order to include the edges of the room. There are other geometric surfaces acting as a junction at the corners that need a more accurate investigation.

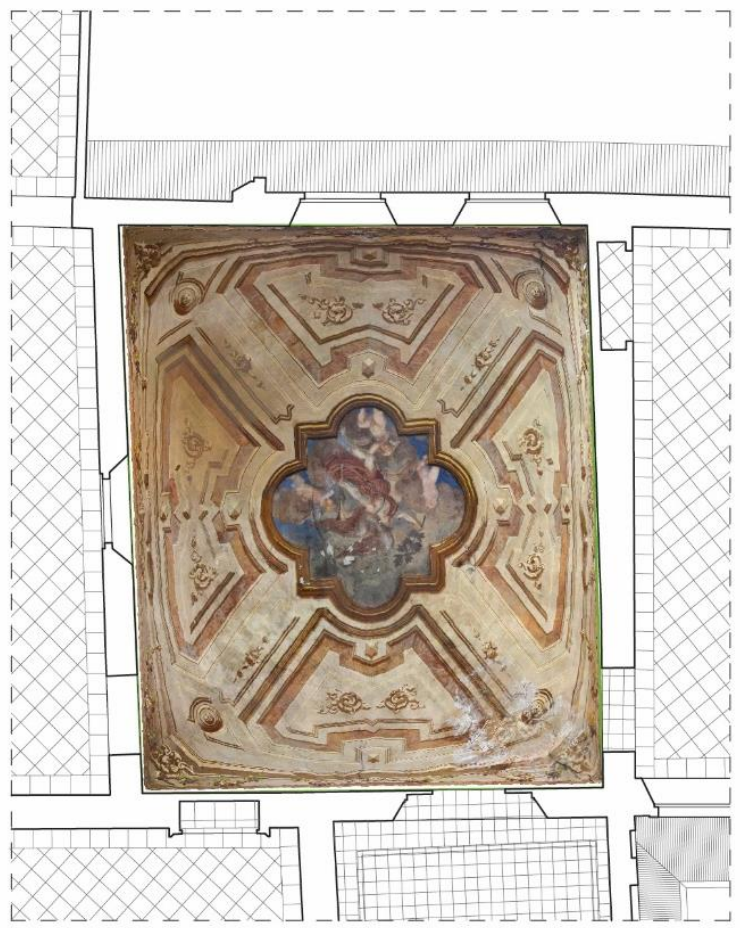

Figure 6. 3D orthoimages of the extrados and the intrados obtained by the photogrammetric image block. 

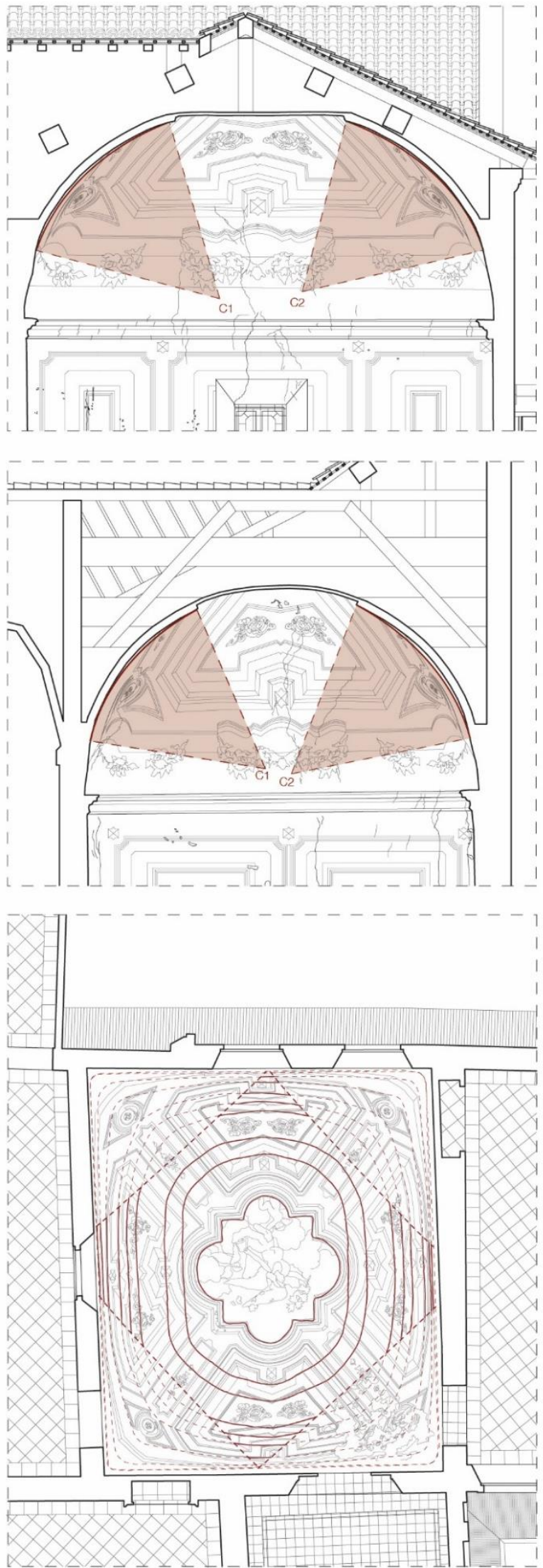

Figure 7. Investigation of circumferences described by intrados profiles along a vertical section of the vault and horizontal slicing extraction.

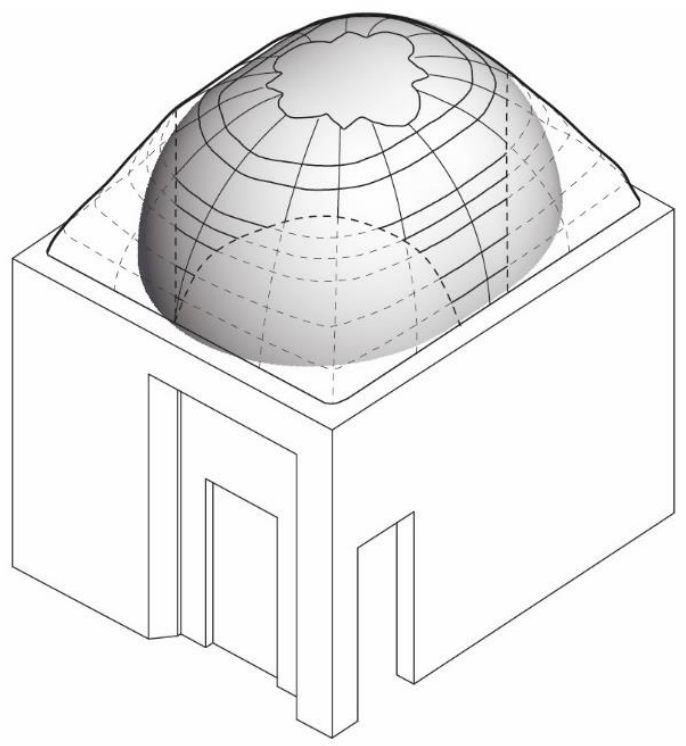

Figure 8. Axonometric view of horizontal and radial slicing of the vault obtained by point cloud of intrados defining a spherical shape.

\subsection{Trompe corner analysis}

Assuming that the structure in the central part is similar to a sphere, it can be combined with an irregular plan thanks to the introduction of a second geometric shape. This is a technical challenge of connecting something round to something square.

A conical pendentive is an architectural element known since ancient times to support domes that resembles the more recent conical trompe described in treatises of stereotomy. These treatises described, through the "trait" method, the models by which every piece of stone can be drawn in all its profiles in relation to the final geometry of the unitary element. Nevertheless, in the case of brick structures, there are many geometric problems related to the shape of the room. This means that built structures can be traced back to pure solids only in general terms, as their main role is to face discontinuities resulting from the plan.

The investigation of a conical shape can begin by looking at the profiles, obtained by vertical sections, that describe the curves of the cone. Assuming the presence of a cone, cutting the surface by plans parallel to the basis, all the curves obtained should match in proportion the basis itself; the curve, instead, that meets the vertex and the centre of the basis, should be a straight line that represents the generatrix, namely the line that generates the solid, by rotating following the circumference-basis.

In this case the section curves, helpful for verification purpouses, are of two kinds: those derived cutting the intrados surface by diagonal planes, but perpendicular to the impost and rotated by $45^{\circ}$ in the direction opposite to the perimeter walls, and thus consider only the volume of the vault, and those derived by tracing the lying of each brick visible in the attic, that, instead, take into account also the constructive technology. The first type sections, that would hypothetically cut the cone by parallel planes at the bottom along its height, are similar to progressively concentric circumferences. The sections of the second type, being parabolas, can help to validate the cone hypothesis, given that the result of cutting a cone by inclined planes is a parabolic line (Figure 9). 

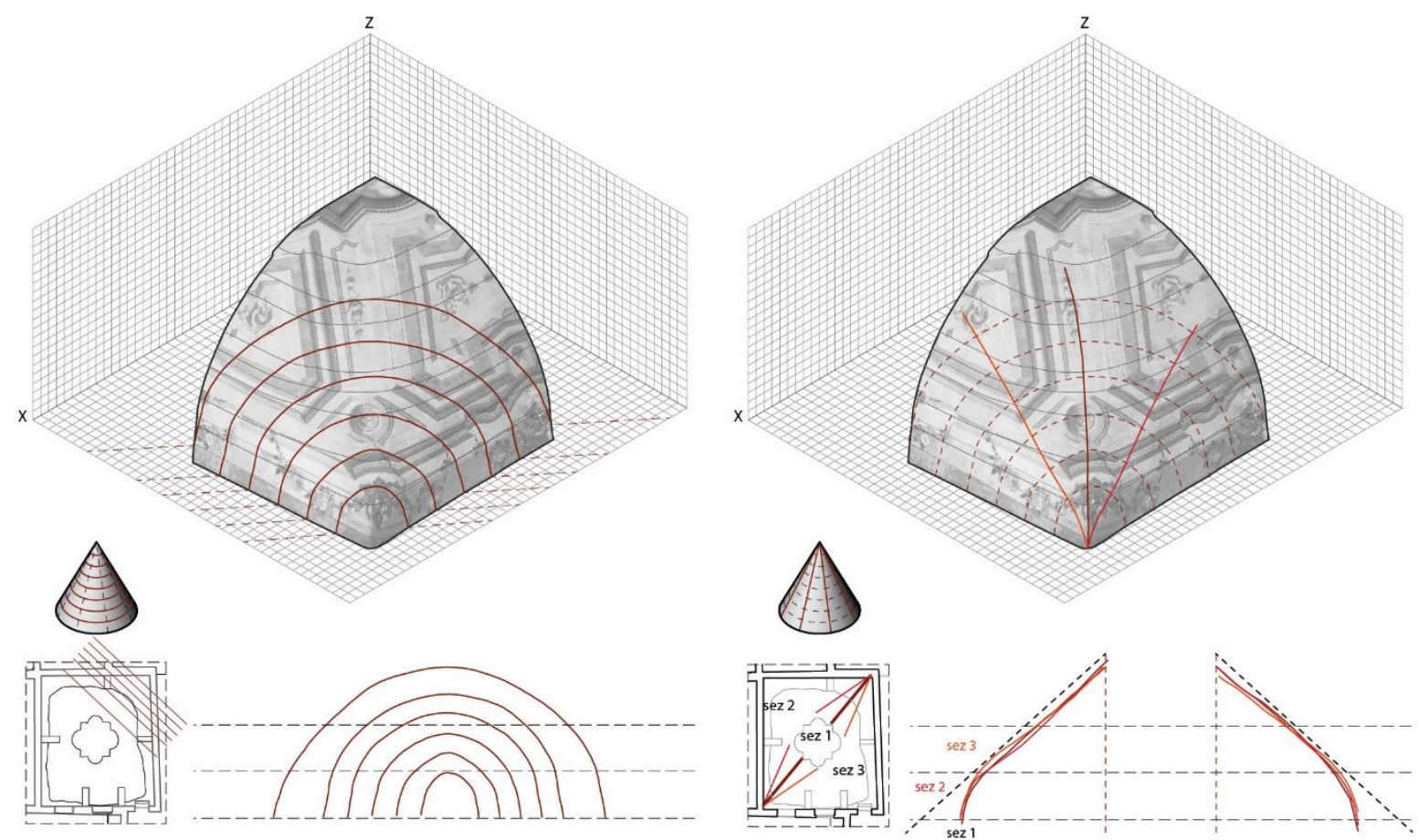

Figure 9. Two different ways of slicing the intrados surface to carry out corner analysis: the first profiles, extracted along bricks arrangement, and the second ones radially to identify the generatrix of a cone.

Another way to confirm the initial hypothesis would be to verify the corner geometry using radial sections obtained cutting the point cloud to identify the generative straight line. The results obtained at the extrados, do not show a clear shape. The radial section that bisects an angle identifies a curvilinear profile that only in the central part resembles a straight line (Figure 10).

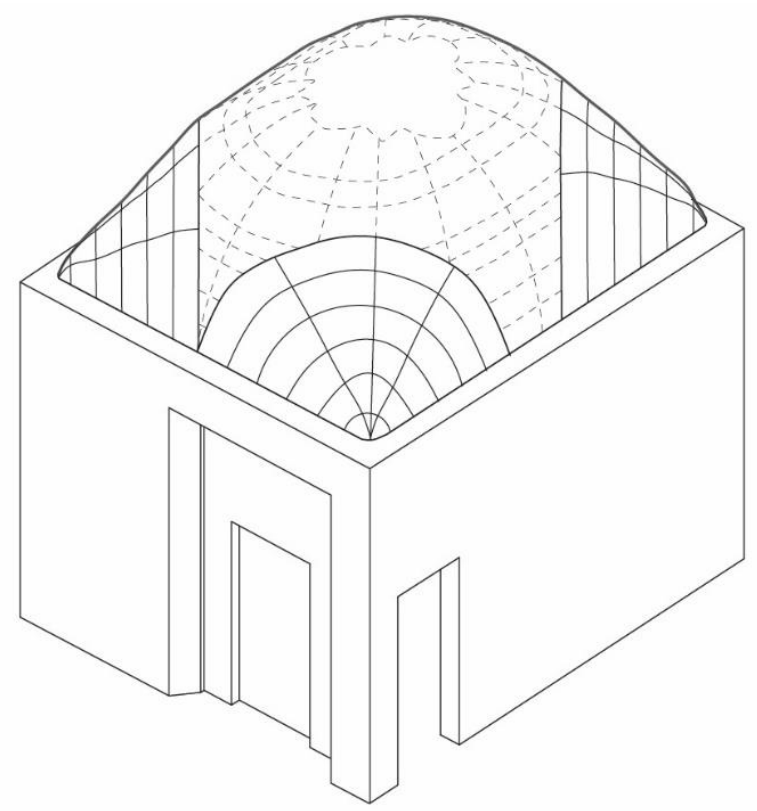

Figure 10. Axonometric view of vault slicing obtained by point cloud of intrados selected under the assumption of cone-shaped corner.
The study of the cones related to the corners is very complex, and the result can only be evaluated qualitatively: this is due to the presence of several irregularities, uncertainties and adjustments in the corners.

The geometric analysis of the radial profiles at the corners highlighted a double curvature shape: at first glance it may look like a cone, whereas it is not. For this matter of fact, we could assume that the construction on the corners did not follow a centring, but a spatial capacity to model the fillet shape like a "trompe", maybe avoiding the centrings.

\subsection{HBIM of the 3D arrangement: the trompe-spherical composite constructive genesis}

The observation of the profiles obtained by cutting the point cloud, resulted in identifying certain hypothetical shapes that could define the vault geometry. If modelling the element by generating NURBS surfaces provides an accurate digital model (based on a survey carried out by means of point cloud acquisition), the simplification of the geometric results can be possible only through the comprehension of the geometry itself. A first check of the simplification process can be carried out by comparing and calculating the distance between the model surfaces that have been measured and the simplified surfaces to be obtained: in the case at issue, a maximum distance of $2 \mathrm{~cm}$ and a medium distance of $1.9 \mathrm{~cm}$ was obtained.

The reconstruction of the vault geometry by means of pure solids is an ideal concept; the real constructive process, instead, follows a different strategy, starting right from the edges of the corners and moving towards the interior. As mentioned above, adopting a constructive technology consisting of inclined arches, both horizontally and vertically, means avoiding the use of any type of centering in building the structure. The identification of repeated circle arches, however, suggests the presence of wooden structures acting as structural support or, at least, as geometric reference to allow a regular construction (Figure 11). 
The HBIM representation through 3D modelling of volumeobject - overcoming the simple mesh-surface -, can represent a great support in the understanding of the construction process. To this aim, those cases where the geometric discontinuities allow to identify the parts of this mixed constructive solutions, for example vaults and domes built on squinches or more complex shapes declined by the oriental tradition have been considered. The photogrammetric surveying of the extrados allows a $3 \mathrm{D}$ reconstruction of the visible arrangement. This process of modelling considers as a basis the NURBS surface coming from the point cloud (Banfi, 2017).

Later, each brick identified as the bidimensional profile of one of its sides - placed any way in the 3D space - acts as a support to place the 3D brick modelled as a BIM element (Figure12).

Starting from a high springer point of bricks, with gradually increasing offsets (each more than the previous one), the current structure is a vault of bricks arranged on the soldier that follow, from each of the four corners, diagonal rows, differently from the perimeter walls.

The Automatic Verification System (Banfi, 2018), applied to the simple cloister vault object respect to the point clouds within the Scan-To-BIM process (Tucci, 2013) highlighted the differences respect to the conceptual model.

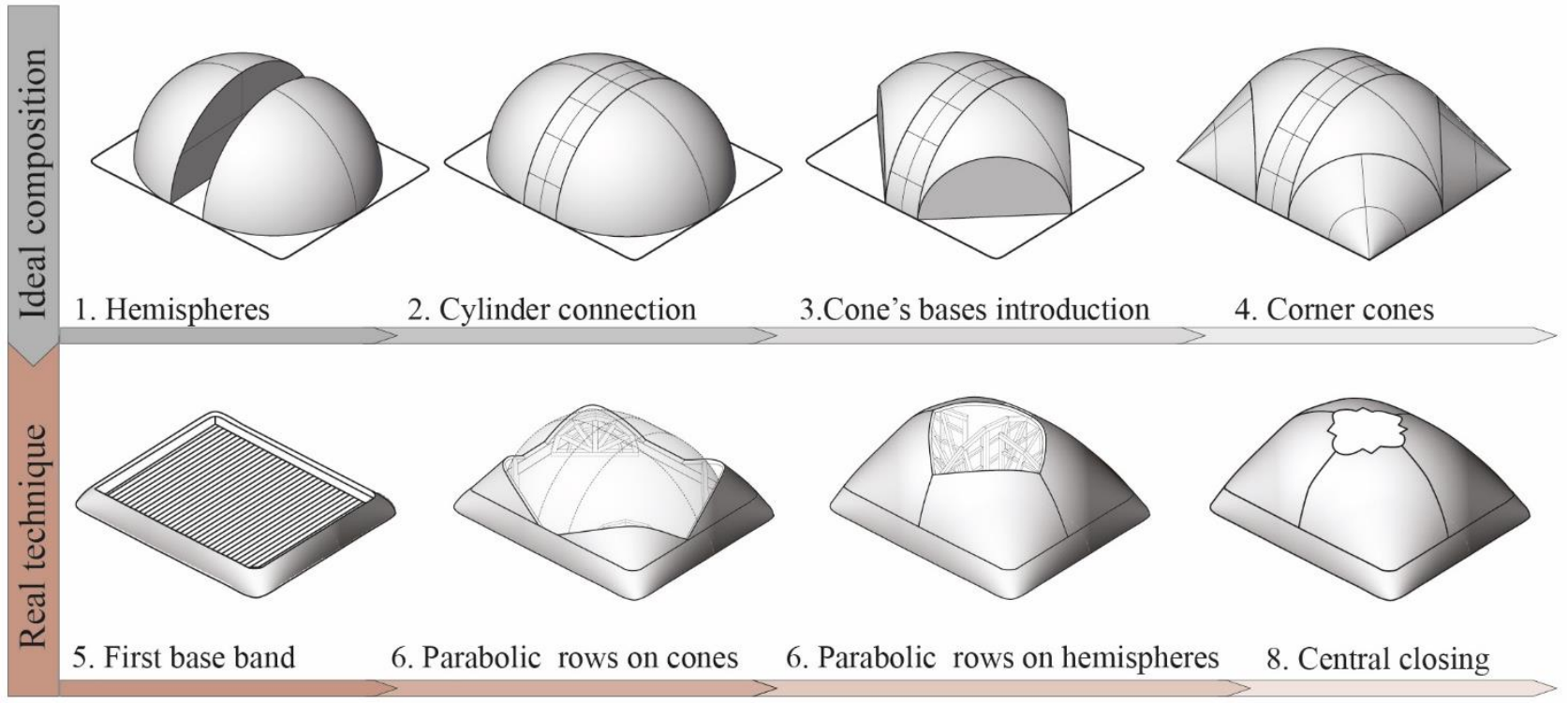

Figure 11. Workflow of geometric analysis of the vault: ideal geometric composition compared to real construction phases.

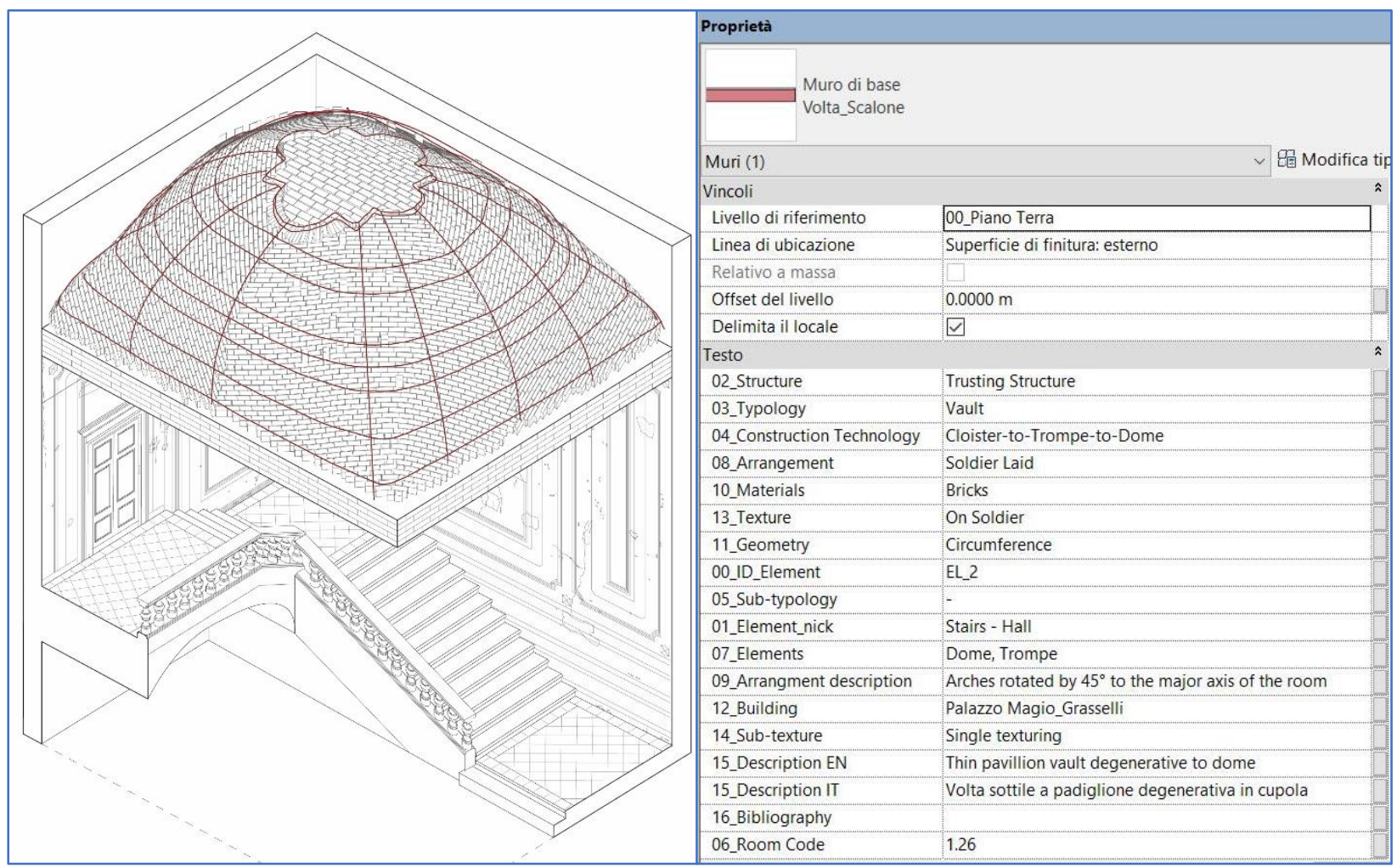

Figure 12. HBIM 3D model and bricks arrangement reconstruction. 
It has been required to introduce a generative based processing within the two different spatial objects (central semi-sphere and 'trompe' on the corners).

One of the first complex constructions based on a diagonal bricks lying was called squinched or trumpet vault by O. Reuther (1939), in German Trompengewölbe, to describe a structure built by joining a number of concentric arches crossing the room until its middle, where they meet to create a central empty space fitted with bricks on folio. As a result, there are no intersection lines along the surface, unlike common cloister vaults.

The planes of the four bearing shells are diagonally inclined inwards and the parabolic layers of brick rows, considered one by one, complete approximately in each corner a conical shape, directed downwards and whose basis lies on the diagonal. The choice of the inclination angle of bricks planes is a determining factor to ensure the connection and the stability of the vault: if, hypothetically, the first brick of each layer, placed on one side of the wall, is assumed to be tangent to the wall, this will affect the shape of the masonry layers. In relation to this kind of structure, the main role is played by the different local curvature of each row of bricks maintaining the inclination of horizontal joints especially along corners where it tends to round off. This constructive technique offers the advantage of taking the pressure of the vault off the side walls, because each row has a greater extension. However, it requires expert bricklayers, able to ensure adhesion of bricks and connection of the bricks from opposite corners, having them meet one another; moreover, sometimes it is necessary to cut the bricks themselves to ensure adherence on the curves.

\section{CONCLUSIONS}

To sum up, it is clear that it is impossible to understand, at first glance, if the geometry springs/comes from constructive techniques or the other way around.

The plans of the four bearing shells are inclined inward along the diagonals, and they are crucial to ensure the stability of the vault. The construction technology of this vaulted system, built by texturing inclined bricks on soldier along the arches progressively layered one on the other, is sped up by avoiding the use of centring: this implies that it could be freely set up without following a specific geometric shape.

The example of another vault of the palace, even if generated on different solids (groined vault), highlights this construction technique, with the intrados readable on the corners without plaster. In the case of the stair vault, the arrangement on the corners is not readable from the extrados, and the thermal image of the intrados would need a more complex climatic heating, in consideration of the dimension of the volume to be realized with the traditional active heating. In any case, it can be concluded that it would appear that the shape of the vault comes from a constructive process rather than a geometric concept. The accurate matching between the vault profiles in the key points and a semi-circular shape, however, can be an evidence of the use of simple wooden elements shaped as quarter of a circle tracing the central sphere, called sesta, used as geometric references.

\section{REFERENCES}

Brumana, R., Condoleo, P., Grimoldi, A., Banfi, F., Landi, A.G., Previtali, M., 2018. HR LOD based HBIM to detect influences on geometry and shape by stereotomic construction techniques of brick vaults. Applied Geomatics 10, 529-543. doi.org/10.1007/s12518-018-0209-3.
Banfi, F., 2017. BIM orientation: grades of generation and information for different type of analysis and management process. In: The International Archives of the Photogrammetry, Remote Sensing and Spatial Information Sciences, 42(2/W5), pp. 57-64

Banfi, F., Chow, L., Ortiz, M. R., Ouimet, C., \& Fai, S. (2018). Building Information Modeling for Cultural Heritage: The Management of Generative Process for Complex Historical Buildings. In Digital Cultural Heritage (pp. 119-130). Springer, Cham.

Brumana, R., Condoleo, P., Grimoldi, A., Landi, A.G., 2017. Le volte a padiglione: forme analoghe, diverse apparecchiature. Varianti in un unico edificio tra XVII e XVIII secolo. Ananke, Special Issue GEORES2017, 99-104.

Delorme, P., 1561. Nouvelles inventions pour bien bastir et a petits fraiz. Federic Morel, Paris.

Frezier, A. F., 1737-1739. La Théorie et la Pratique de la Coupe des Pierres et des bois, pour la construction des voutes et autres parties des bâtiments. Traité de stereotomie à l'usage de l'architecture. J.-D. Doulsseker le fils, Strasburgo,

Grimoldi, A. and Landi, A. G., 2012. The spread of the XVIIth century vaults in Cremona. The case study of Magio Grasselli Palace. Proceedings of $8^{\text {th }}$ International Conference on Structural Analysis of Historical Construction. Jerzy, J., (ed.). 1136-1144.

Guarini, G., 1671. Euclides Adauctus. Bartholomaei Zapatae, Torino.

Guarini, G., 1737. Architettura civile. Appresso Gianfrancesco Mairesse, Torino.

Landi, A., G., 2019. A XVth Century Diamond Ashlar Façade: The Case Study of Palazzo Raimondi in Cremona. Structural Analysis of Historical Construction. Aguilar, R., Torrealva, D., Moreira, S., Pando, M., Ramos, L.F. (Eds.) 587-595, doi.org/10.1007/978-3-319-99441-3_63

Landi, A. G., 2011. Riforme edilizie in una dimora aristocratica cremonese: palazzo Magio-Grasselli. In: Landi A. (Ed.), Patrizi, notabili, costruzione della città. Palazzo Magio-Grasselli a Cremona tra civitas e urbs. U. Allemandi, Torino, 33-116.

Oreni, D., Brumana, R., Georgopoulos, A., Cuca B., 2013. HBIM for conservation and management of built heritage: towards a library of vaults and wooden bean floors. ISPRS Annals of Photogrammetry, Remote Sensing and Spatial Information Sciences, Grussenmeyer, P., (ed.), vol. II-5/W1, 215-221.

Reuther, O, 1939. Sassanian Architectur. A Survey of Persian Art, Pope, A., (ed.). Oxford University Press, London. 493-578.

Tucci, G., Bonora, V., Guardini, N., 2013. Analysis of the factors affecting 3D models resolution-application to the recording of vaults in sangallo's house ISPRS Annals of the Photogrammetry, Remote Sensing and Spatial Information Sciences, 2 (5/W1), pp. 307-312. DOI: 10.5194/isprsannals-II-5-W1-307-2013.

Wendland, D., 2008. Lassaulx und der Gewölbebau mit selbsttragenden Mauerschichten: neumittelalterliche Architektur um 1825 - 1848. Imhof, Petersberg. 